\title{
Computational Modelling and Prediction of Consequences in Case of Accidental Releases of Hazardous Substances in an Industrial Plant
}

\author{
Vlad Mihai Pasculescu ${ }^{1,}{ }^{,}$, Marius Simion Morar ${ }^{1}$, Cristian Raul Cioara ${ }^{1}$, Ligia Ioana Tuhut ${ }^{1}$, and Andrada Denisa Babut ${ }^{1}$ \\ ${ }^{1}$ National Institute for Research and Development in Mine Safety and Protection to Explosion - INSEMEX, 32-34 G-ral Vasile Milea \\ street, 332047, Petrosani, Hunedoara county, Romania
}

\begin{abstract}
Storing relatively large amounts of hazardous materials under certain conditions can lead to high-risk situations. In industrial units, the assessment of the amplitude and severity of the consequences of the identified major accidents is done in order to provide data on site intervention and emergency planning. This study aims to assess the consequences of untimely releases of hazardous explosive / toxic substances in an industrial unit by graphical modelling and analysis of such accident scenarios using specialized software tools. The main activity of the industrial unit under study consists in the manufacture, processing and marketing of essential oils and their derived products.
\end{abstract}

\section{Introduction}

The purpose of the major risk prevention policy and the purpose of the safety management system is to implement within the industrial units the legal provisions to prevent major accidents, and in case of a major accident, to succeed, through the actions taken, to minimize the impact and amplitude.

Given the legal provisions in force on the control of major accident hazards involving dangerous substances industrial units have to adopt policies to prevent major accidents involving dangerous substances and must have appointed a responsible for security management.

The policy for the prevention of major accidents involving dangerous substances on site is drawn up in order to achieve, in a short time, in an organized and unitary way, the measures of protection, intervention and reduction of the effects resulting from a major accident involving dangerous substances.

The document on major accident prevention policies, prepared in writing, based on the major accident hazards, identified on the site of a company, defines the overall objectives of the operator and the principles of action for the control of major accident hazards.

Protection and intervention measures refer to dangerous substances that are used or produced in the economic unit under study.

The assessment of the amplitude and severity of the consequences of the major accidents identified is made in order to provide data on site intervention and emergency planning [1].

\section{Major hazards identification and assessment}

Storing relatively large amounts of hazardous materials under certain conditions can lead to high-risk situations. The hazard of a major accident is determined by the coexistence of several risk factors, as presented in Table 1 :

Table 1. Risk factors

\begin{tabular}{|c|l|}
\hline & \multicolumn{1}{|c|}{ Probable risk factor } \\
\hline \multirow{3}{*}{ Chemical } & $\begin{array}{l}\text { - storage and transport of toxic and } \\
\text { environmentally dangerous substances; } \\
\text { - accidental spills of toxic or environmentally } \\
\text { hazardous substances; } \\
\text { - toxic flue gas dispersions in case of fire. }\end{array}$ \\
\hline Fire / & $\begin{array}{l}- \text { storage of combustible and flammable } \\
\text { substances; } \\
\text { Explosion }\end{array}$ \\
$\begin{array}{l}\text { - use of flammable substances at boiling } \\
\text { temperatures. }\end{array}$ \\
\hline
\end{tabular}

The activity carried out on the studied site involves the storage, handling and processing of chemicals (hazardous substances), the presence of this type of product being the defining aspect of safety management and as such its concept is based mainly on good management of storage and handling.

In the process of identifying and assessing major hazards, documents should be used regarding: the properties of the substances that may be present on the site and the environmental monitoring as well as the results of investigations carried out following possible incidents and accidents in the unit or similar units [2]. It ensures a clear link between the identified risk and the measures taken, through a hierarchical approach, in order

\footnotetext{
* Corresponding author: vlad.pasculescu@ insemex.ro
} 
to avoid major accidents or, ultimately, to minimize the effects by applying safety practices at each workplace [3].

Within the article, there is carried out a systematic analysis of site risks, applying quantitative analysis methods by modelling accident scenarios using specialized software tools $[4,5,6,7]$.

\section{Considerations on quantitative risk assessment of toxic dispersions}

Simple models for hazard identification and qualitative risk analysis are not always sufficient and as such it is sometimes necessary to use detailed assessments [8]. There are several methods for carrying out a quantitative risk assessment. The choice of a particular technique is specific to the analyzed accident scenario.

To assess the risk associated with potential major accidents identified by qualitative risk analysis, the methodology "based on consequences" is also used; also called "deterministic approach" which is based on assessing the consequences of possible accidents, without quantifying the probability of these accidents, thus avoiding the inherent uncertainties that arise in the explicit quantification of the frequencies of potential accidents.

This method has a rational basis similar to the "worst case scenario imagined". It is considered that if, for the worst case scenario, sufficient measures are taken to protect the population, then, for each possible accident, less serious than the worst, measures will also be sufficient to protect the population.

The consequences of accidents are taken into account quantitatively, by calculating the distance at which the physical quantity describing the consequences (in this case the toxic concentration) reaches a limit value (threshold) corresponding to the beginning of the manifestation of undesirable effects. The thresholds used in this paper are in accordance with the legislation of some EU countries (values are not uniform at EU level).

In addition to the distance corresponding to the lethal threshold value of the physical quantity that describes the consequences, another distance is estimated, corresponding to the beginning of the "irreversible effects". This distance is used to separate areas with a sensitive population (schools, hospitals) or densely populated areas from sources of danger.

The effects generated by the occurrence of an accident depend on the type of scenario that defines the analysed accident and the value of the determined specific indicator. Damage caused by toxic dispersions can be estimated based on the following threshold values [9]:

- $\quad$ ERPG 3 represents the value of the concentration in air of a substance expressed in ppm or $\mathrm{mg} / \mathrm{m}^{3}$, above which it is foreseeable that most people, including susceptible individuals, will suffer lifethreatening effects or may cause death;

- $\quad$ ERPG 2 represents the value of the concentration in the air of a substance expressed in ppm or $\mathrm{mg} / \mathrm{m} 3$, above which it is foreseeable that most people, including susceptible individuals, will suffer irreversible or serious long-term effects affecting health or self-evacuation

- $\quad$ ERPG 1 represents the value of the concentration in the air of a substance, expressed in ppm or $\mathrm{mg} / \mathrm{m} 3$, above which it is predictable that most people, including susceptible individuals, will suffer appreciable discomfort, irritation, ie asymptomatic effects that do not affect the senses. However, the effects do not cause disability, are transient and reversible when exposure ceases

When these limits are not available, the AEGL (1, 2 and 3 ) or Teels (1, 2 and 3) thresholds are used.

\section{Problem setup and numerical study}

\subsection{General description of the industrial unit}

\subsubsection{Activity}

The main activity carried out on site is the manufacture and processing of essential oils and their derived products. Essential oils and derived products are used in the cosmetics, pharmaceutical, perfumery and aromatherapy industries.

The activities carried out on site, in the safety-relevant parts of the site, are those associated with the processing, packaging and storage of the hazardous substances used. These activities are:

- $\quad$ reception and unloading of dangerous substances raw materials, auxiliaries from cars;

- $\quad$ the actual storage in the storage warehouses;

- their processing in the installations in the production hall;

- $\quad$ packaging of finished products and fractions for storage;

- $\quad$ storing them in the appropriate warehouses;

- loading and shipping the finished products by car.

Other on-site activities related to the main activities are:

- $\quad$ providing utilities: water, gas, electricity;

- office activities;

- preventing and extinguishing fires, combating accidental pollution;

- $\quad$ waste management.

The main hazards that can cause a major accident on site are [10]:

- fire hazard;

- explosion hazard;

- hazards of air pollution and intoxication of personnel with toxic flue gases resulting in case of fire or explosion;

- hazard of soil pollution with contaminated water resulting from a fire;

- hazard of soil pollution in case of spills of hazardous substances on unprotected surfaces;

- chances of intoxication in case of ingestion, in particular of substances with high toxicity. 


\subsubsection{Location and vulnerable points}

The objective is located in an industrial and peripheral area in the north-eastern part of a territorial administrative unit of municipal type, in the vicinity of the site being identified several vulnerable areas in case of major industrial accidents (up to a distance of about 5 $\mathrm{km}$ ) and which are shown in Table 2.

The geospatial location of the vulnerable areas $\mathrm{i}$ are shown in Figure 1.

The balance of areas on the industrial site is as follows:

- $\quad$ total surfacce: $37.910 \mathrm{~m}^{2}$;

- $\quad$ built area: $6.228 \mathrm{~m}^{2}$;

- free surface: $12.317 \mathrm{~m}^{2}$ din care:

- $\quad$ grassy surface: $10.000 \mathrm{~m}$;

- $\quad$ orchards: $2.317 \mathrm{~m}^{2}$.

- the surface occupied with networks, access roads, concrete platforms: $19365 \mathrm{~m}^{2}$.

Currently, only one economic operator operates on
Table 2. Identified vulnerable points

\begin{tabular}{|c|c|}
\hline Type & Codification \\
\hline Educational institutions & $1,2,3,4,5,6,7,8,9,10,11$ \\
\hline Churches & $12,13,14,15,16,17,18,19$ \\
\hline Hospitals & 20 \\
\hline Shopping centres & $21,22,23$ \\
\hline Public institutions & $24,25,26,27,28$ \\
\hline Residential areas & $29,30,31,32,33,34$ \\
\hline
\end{tabular}
the site.

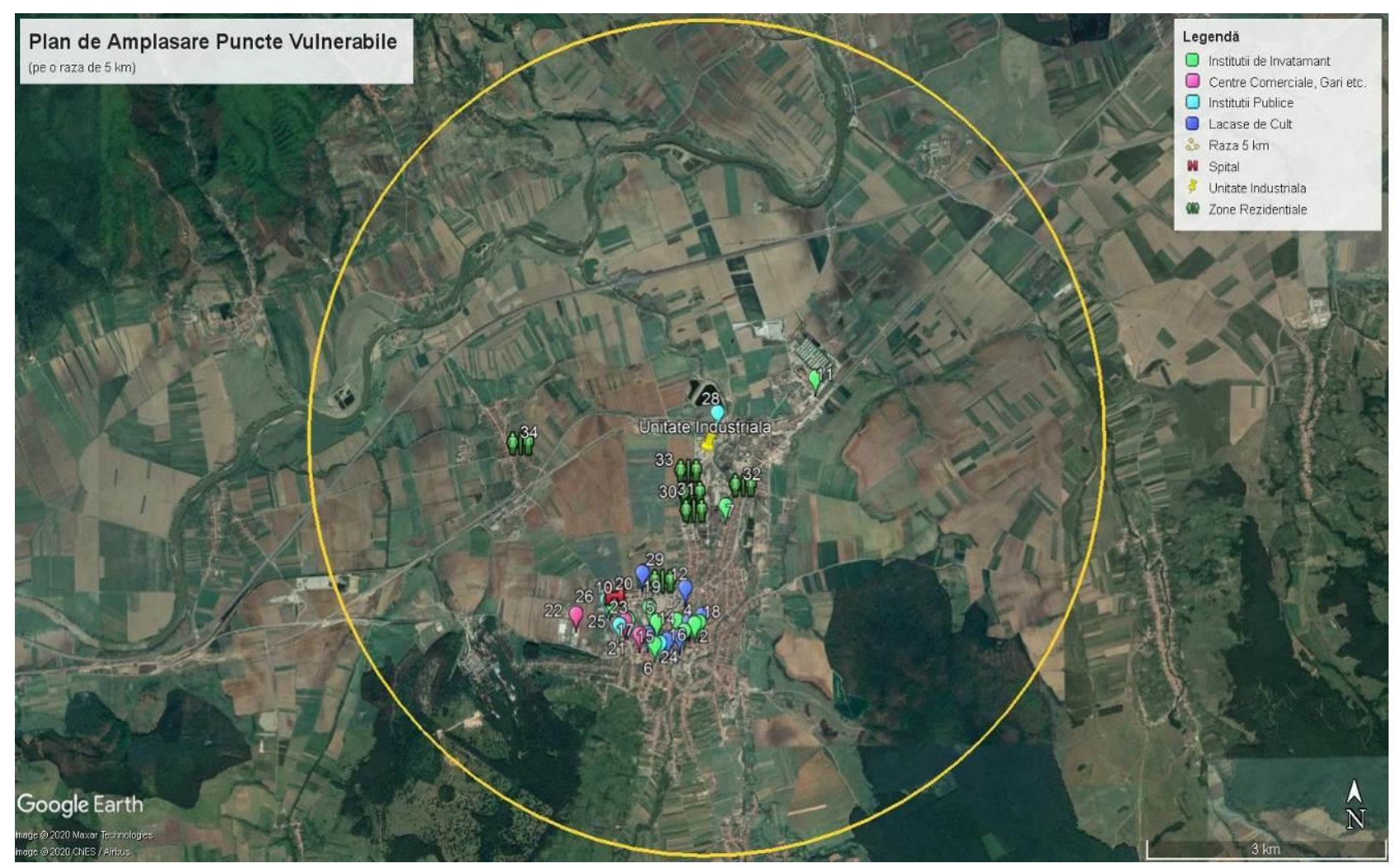

Fig. 1. Location plan of vulnerable points (within a radius of about $5 \mathrm{~km}$ )

\subsection{Software tools}

For the calculation of indicators for major accident scenarios was used Phast 8.23 , software with which computer simulations can be performed, bringing a huge opening in the field of research through the possibilities of analyzing situations that may pose a potential hazard to people, property or the environment and to quantify them according to their severity [11].

The consequences can then be managed or reduced by designing the industrial process or installation, modifying operational procedures or by implementing other measures to eliminate them.

\subsection{Selection and modelling of typical site- specific accidents}

The installations from the industrial unit may be subject to leakage of hazardous liquid substances and vapor emissions caused by $[12,13]$ :

- Leaks from pumps, flanges, valves and other fittings; 
- Cracks due to mechanical stress: vibration, weakening of the material caused by high temperatures, corrosion, material defects or improper maintenance;

- Human error through wrong manoeuvres or other non-compliant operations. The occurrence of leaks in technological installations is favoured by:

$\circ$ Existence of joints and other sealing elements in tanks, pumps, reactors and pipes

- Relatively high temperatures (above evaporation temperature) at distillation / rectification columns;

- Unloading of products from means of transport (mobile equipment).

In the case of leakages of liquid substances with a certain degree of volatility, evaporation can produce dispersions which, depending on the characteristics of the substance, can be toxic and / or flammable

Due to the existing protection systems in case of liquid leaks, they will reach the drainage systems (retention tanks, collection basins) which limits the spreading surface of a possible leak and therefore the evaporation surface and implicitly the amount of vapours in the dispersion.

Also, a good positioning of the gutters and drains can greatly limit the surface of a possible leak on platforms outside the actual retention system.

The existence of covered collection basins is also very important because it does not allow the accumulation of liquid in the retention tank or on concrete surfaces and transfers it to a closed system where evaporation is greatly diminished and the vapours formed do not disperse directly into the air.

Leaks are dangerous due to:

- risk of poisoning personnel. Exposure to high concentrations of highly toxic products may result in severe intoxication of operating or response personnel.

- $\quad$ fire and explosion hazard. Vapours of flammable substances may ignite and cause fire.

- danger of soil, surface and groundwater pollution. Many of the substances on the site are environmentally hazardous and if they reach unprotected areas in large quantities and concentrations can cause local pollution.

The hypotheses that were taken into account in performing the simulations are:

- the measurement height (relative to ground level) of the airborne concentration of the toxic substance has no significant effect on dispersion, as such the representation of the results is made for the concentrations calculated at a height of $10 \mathrm{~m}$ above the ground.

- wind speed significantly influences the characteristics of the toxic cloud, in the sense that a high speed generates an elongated cloud, which propagates quickly over a relatively long distance, with a relatively rapid decrease in concentrations and a low speed generates a wider cloud, which propagates slowly over a long distance, with a slow decrease in concentrations. Areas affected by high concentrations and exposure times are larger in the case of low wind speeds and as such this situation is more dangerous. In the presented simulations a speed of $1 \mathrm{~m} / \mathrm{s}$ is used for the most unfavourable situation and $3 \mathrm{~m} / \mathrm{s}$ for the average situation.

- atmospheric stability is another factor that greatly influences the dispersion, the state of atmospheric stability being the most unfavourable and as such used in the presented simulations. Class E is used for the most unfavourable situation and class D for the average situation;

- the relative humidity of the air does not significantly influence the dispersion and as such we used the value of $50 \%$ for the unfavorable situation and $75 \%$ for the average.

- atmospheric temperature is one of the parameters that does not significantly influence the dispersion but also the evaporation rate of some liquids. As such, in the presented simulations we used a temperature of $37{ }^{\circ} \mathrm{C}$ for the unfavourable situation and $9{ }^{0} \mathrm{C}$ for the average situation, which can be considered representative for the location area of the analysed objective.

- for the roughness of the land, the urban type was used. This type of terrain has high roughness and high turbulence, because the chemical cloud moves on a surface with many friction-generating elements, such as trees or small buildings (residential, industrial areas or forests).

Scenarios of accidents with major consequences were selected for the quantitative risk analysis, although the risk of occurrence of events with serious consequences is low or at most medium. A reasonable scenario as well as a worst case scenario were selected and analysed.

In the following there are presented the results obtained by quantitative risk analysis, by modelling possible scenarios that result in the release into the atmosphere of toxic / explosive hazardous substances located on the site of the industrial unit.

\subsubsection{Scenario 1 - The leakage of the entire quantity of substance $(500 \mathrm{~kg})$ from a tank located in the area of the production hall}

- Hazardous substance: Chlorine, Quantity: 500 kg, normal atmospheric temperature and pressure.

It is considered the worst case scenario, in which the entire amount of existing chlorine leaks from the tank.

The simulation results are presented in the following:

A. Unfavourable weather conditions (Figure 2 - Figure 3)

Dangerous area: Toxic area of the vapour cloud

- ERPG $1=1 \mathrm{ppm}$

- ERPG $2=3$ ppm

- ERPG $3=20 \mathrm{ppm}$ 


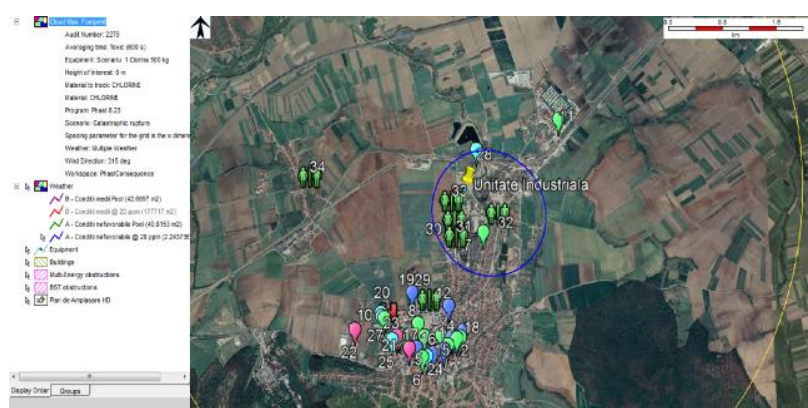

Fig. 2. Toxic area of the gas cloud

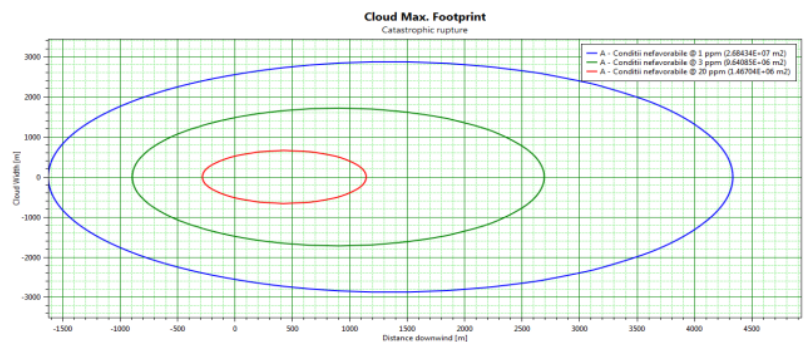

Fig. 3. Toxic cloud maximum footprint

B. Average weather conditions (Figure 4 - Figure 5) Dangerous area: Toxic area of the vapour cloud

- ERPG $1=1 \mathrm{ppm}$

- ERPG $2=3$ ppm

- ERPG $3=20$ ppm

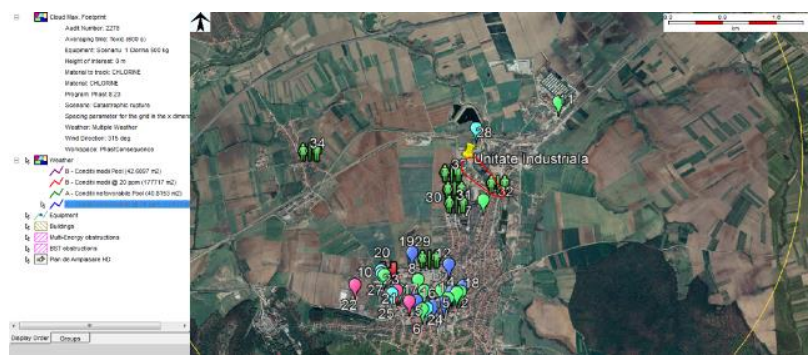

Fig. 4. Toxic area of the gas cloud

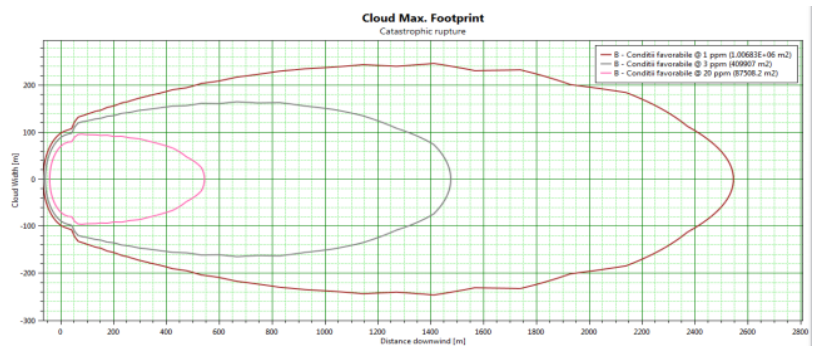

Fig. 5. Toxic cloud maximum footprint

4.3.2 Scenario 2 - The leakage of the entire quantity of substance from a $1 \mathrm{~m}^{3}$ container located on the weighing platform

- Hazardous substance: Hydrogen chloride, Quantity: $1 \mathrm{~m}^{3}$, normal atmospheric temperature and pressure.
It is considered a reasonable scenario, in which a breakdown occurs and the amount of hydrogen chloride existing leaks from the tank.

The simulation results are presented in the following:

A. Unfavourable weather conditions (Figure 6 - Figure 7) Dangerous area: Toxic area of the vapour cloud

- ERPG $1=3$ ppm

- ERPG $2=20$ ppm

- ERPG 3 = 150 ppm

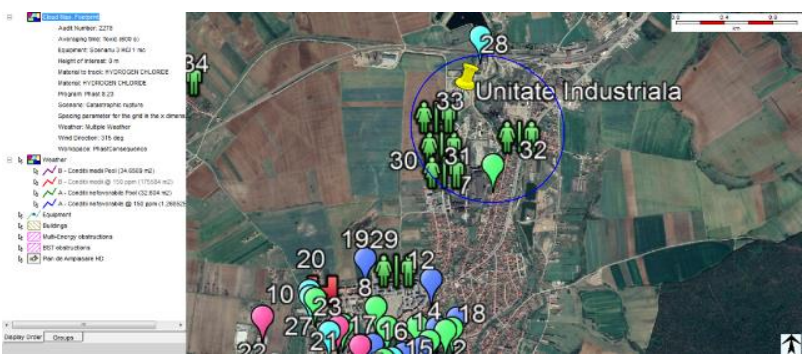

Fig. 6. Toxic area of the gas cloud

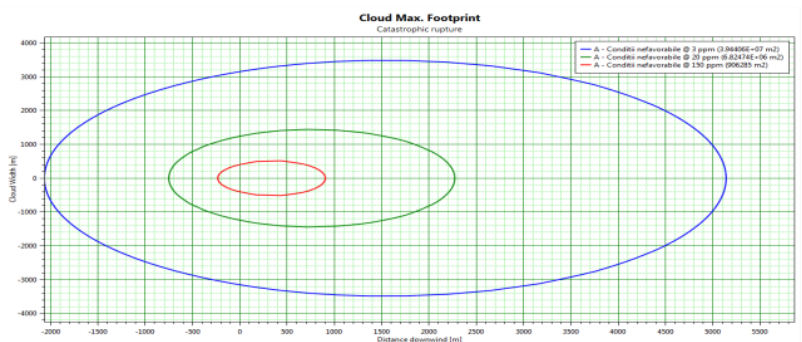

Fig. 7. Toxic cloud maximum footprint

B. Average weather conditions (Figure 8 - Figure 9)

Dangerous area: Toxic area of the vapour cloud

- ERPG $1=3 \mathrm{ppm}$

- ERPG $2=20 \mathrm{ppm}$

- ERPG $3=150$ ppm

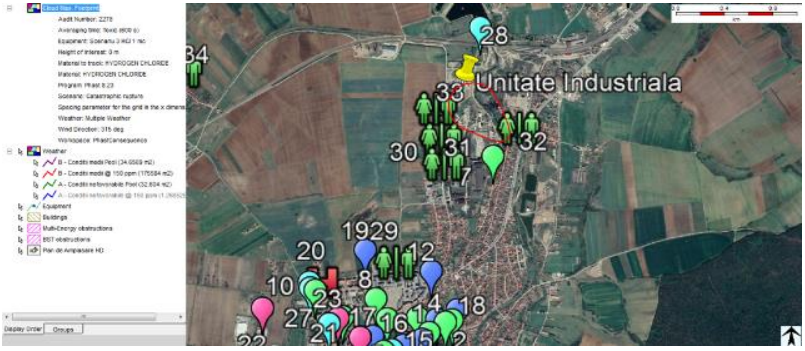

Fig. 8. Toxic area of the gas cloud

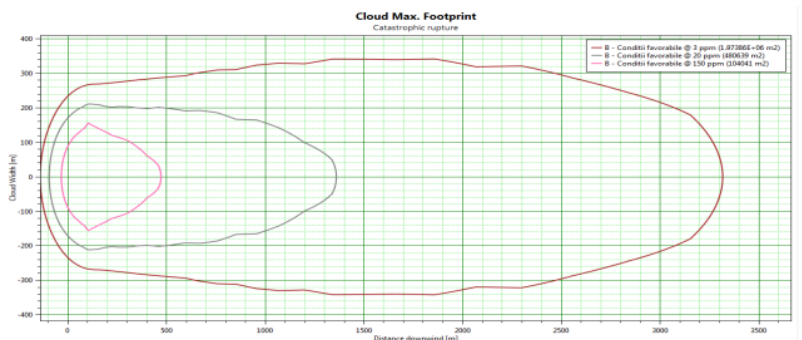

Fig. 9. Toxic cloud maximum footprint 

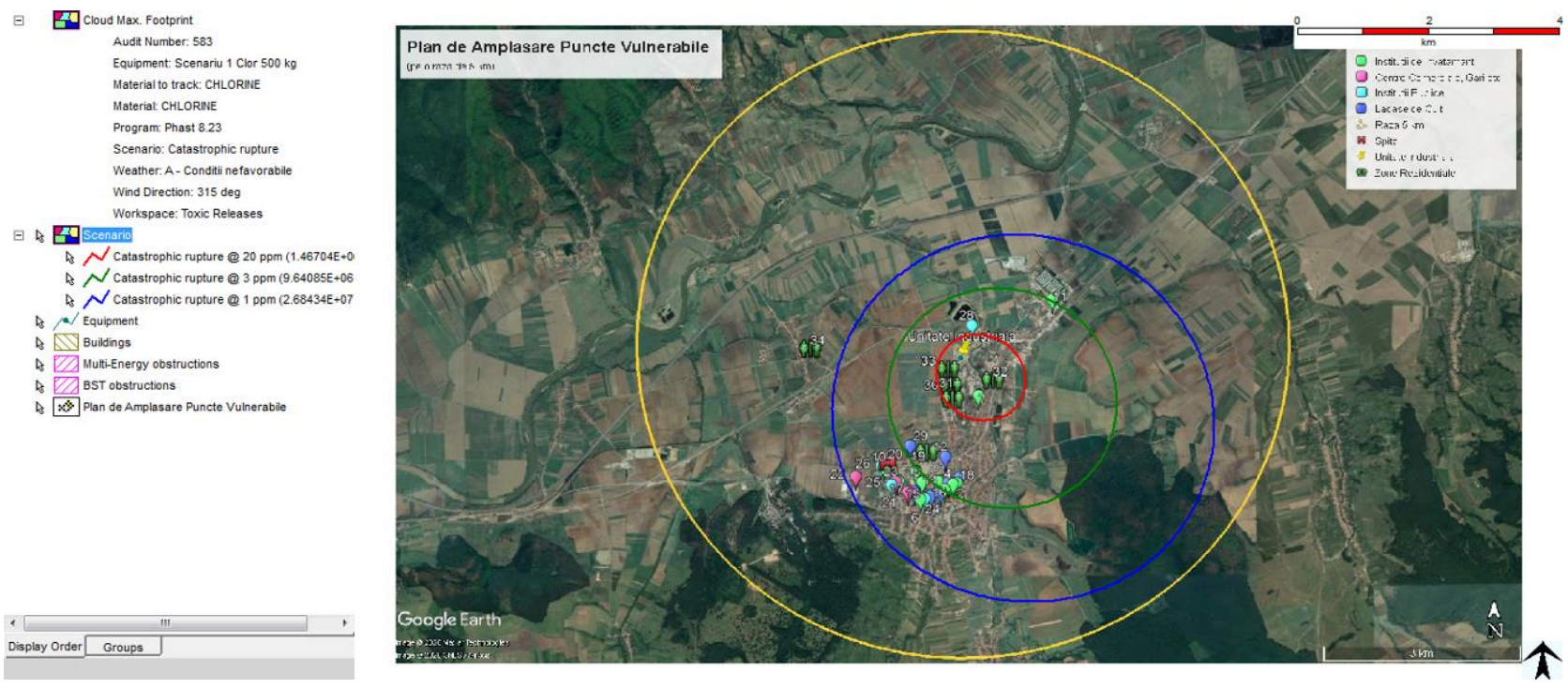

Fig. 10. Toxic cloud - ERPG levels (Chlorine leakage, $500 \mathrm{~kg}$, unfavourable weather conditions)
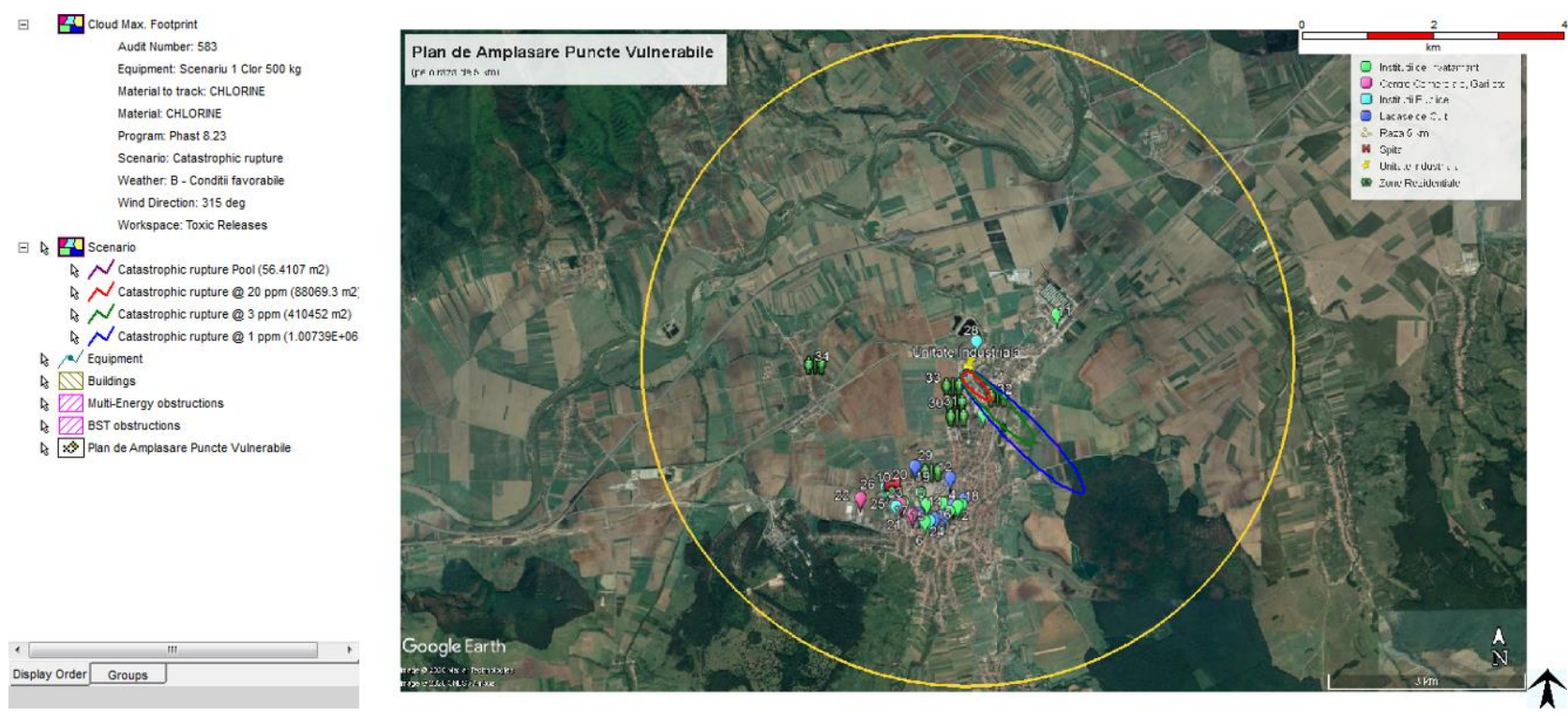

Fig. 11. Toxic cloud - ERPG levels (Chlorine leakage, $500 \mathrm{~kg}$, average weather conditions)

\section{Conclusions}

Following the modelling of the 2 possible accident scenarios, the following conclusions can be drawn:

For Scenario 1 - leakage of the entire quantity of substance $(500 \mathrm{~kg})$ from a tank located in the area of the production hall

- $\quad$ unfavourable weather conditions: points $30(640 \mathrm{~m})$, $31(790 \mathrm{~m}), 32(580 \mathrm{~m}), 33(350 \mathrm{~m})$ (residential areas), educational unit $7(870 \mathrm{~m})$ and water treatment plant $28(360 \mathrm{~m})$ are located in the risk area - Figure 10;

- the identified vulnerable point located in the area of attention is the residential area $32(580 \mathrm{~m})$ - Figure 11
For Scenario 2 - leakage of the entire quantity of substance from a $1 \mathrm{~m}^{3}$ container located on the weighing platform:

- unfavourable weather conditions: the residential areas adjacent to the industrial unit are in the toxic area of the vapour cloud. Also, the water treatment plant 28 and the educational unit 7 are in the area of attention (tangential to the cloud of toxic gases) Figure 12;

- $\quad$ average weather conditions: toxic area of the cloud does not reach any vulnerable points - Figure 13. 

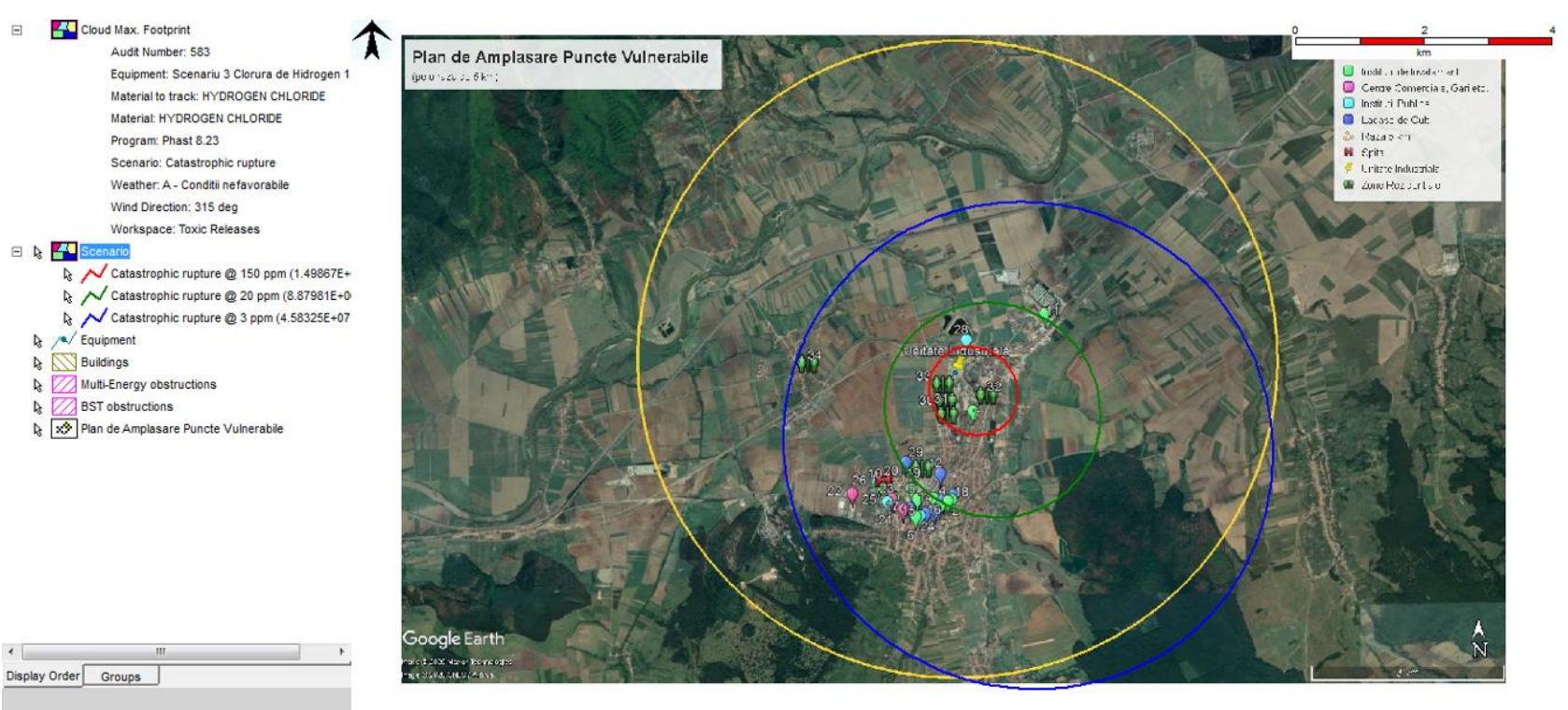

Fig. 12. Toxic cloud - ERPG levels (Hydrogen chloride leakage, $1 \mathrm{~m}^{3}$, unfavourable weather conditions)
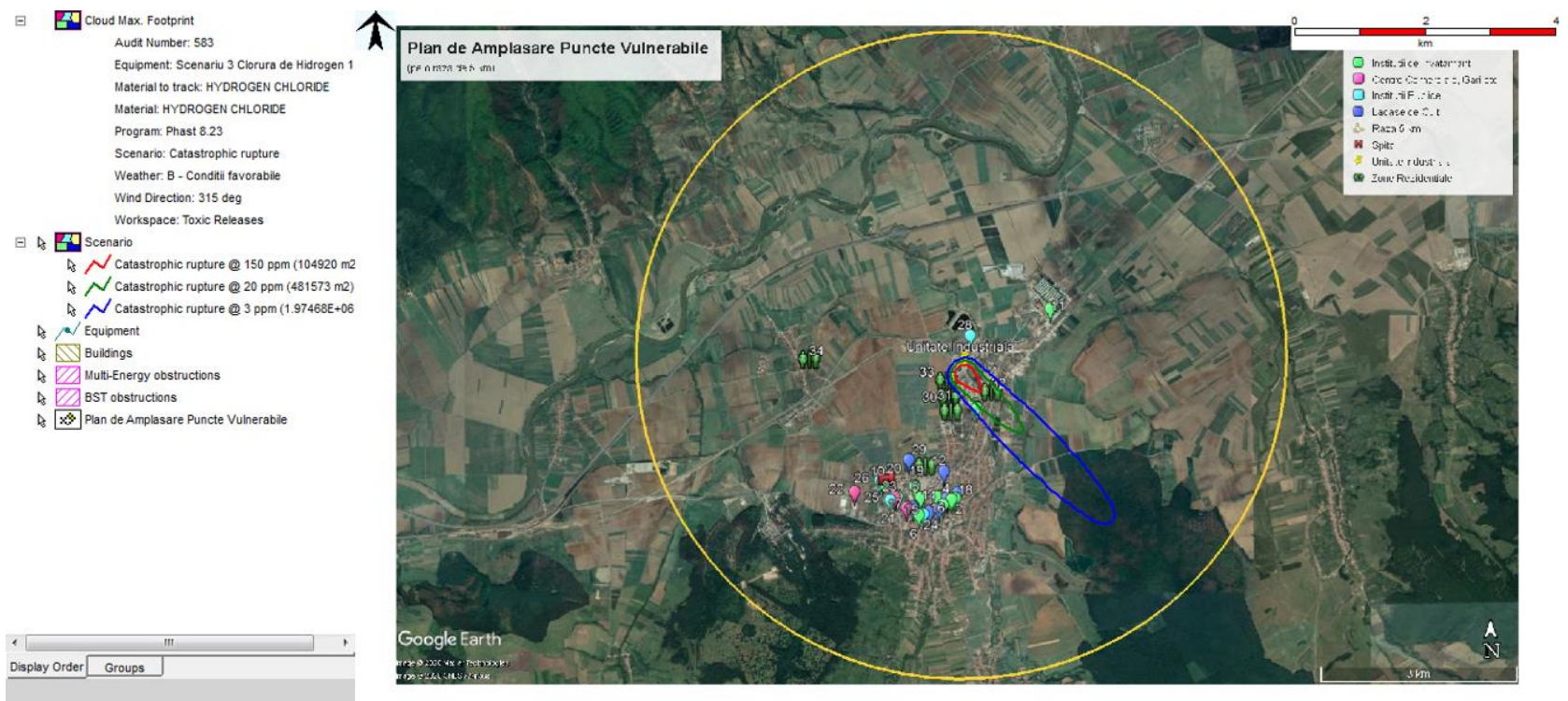

Fig. 13. Toxic cloud - ERPG levels (Hydrogen chloride leakage, $1 \mathrm{~m}^{3}$, average weather conditions)

This paper was developed within the NucleuProgramme, carried out with the support of Romanian Ministry of Education and Research, project no. PN-1921-02-01, project title: Techniques and solutions for developing the scientific and technical competences for prevention and protection to explosions (in Romanian: Tehnici si solutii pentru dezvoltarea competentelor stiintifice si tehnice de prevenire si protectie la explozie).

\section{References.}

1. G. B. Babut, R. I. Moraru, Quality - Access to Success, 19 (166), 133-144, (2018)

2. G. D. Vasilescu, E. Ghicioi, S. Simion, V. M. Pasculescu, Appl Mech Mater, 430, 276-280, (2013)

3. V. M. Pasculescu, S. M. Radu, E. Ghicioi, D. Pasculescu, T. Niculescu, Proceedings of the 14th International Multidisciplinary Scientific GeoConference SGEM 2014, 1 (2), 43-50, (2014)
4. F. G. Popescu, D. Pasculescu, M. D. Marcu, V. M. Pasculescu, Mining of Mineral Deposits, 14 (4), 40 46, (2020)

5. M. Leba. A. Ionica, R. Dobra, V. M. Pasculescu, Environ Eng Manag J, 13 (6), 1365-1370, (2014)

6. V. M. Pasculescu, E. Ghicioi, M. S. Morar, D. Pasculescu, M. C. Suvar, Quality - Access to Success, 20, 25-30, (2019)

7. V. M. Pasculescu, N. I. Vlasin, E. Ghicioi, G. D. Florea, M.C. Suvar, Environ Eng Manag J, 18 (4), 889-900, (2019)

8. D. Pasculescu, L. Pana, V. M. Pasculescu, F. Deliu, Mining of Mineral Deposits, 13 (2), 1-16, (2019)

9. Emergency Response Planning Guidelines (ERPG) and Workplace Environmental Exposure Level (WEEL) Handbook, AIHA Guideline Foundation, (2017)

10. M. Suvar, D. Cioclea, I. Gherghe, V. Pasculescu, Environ Eng Manag J, 11 (7), 1235-1239, (2012) 
11. Phast Software features. Available on https://www.dnvgl.com/services/process-hazardanalysis-software-phast-1675

12. V. M. Pasculescu, N. I. Vlasin, D. Florea, M.C. Suvar, Quality - Access to Success, 18, 97-102, (2017)

13. V. M. Pasculescu, N. I. Vlasin, M. C. Suvar, C. Lupu, Environ Eng Manag J, 16 (6), 1323-1330, (2017) 